\title{
Nitrogen source influences the antioxidative system of soybean plants under hypoxia and re-oxygenation
}

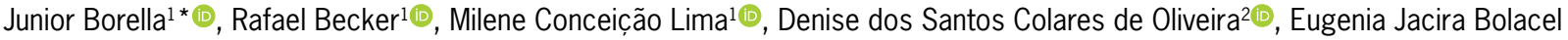 \\ Braga $^{10}$, Ana Claudia Barneche de Oliveira ${ }^{3(0)}$, Luciano do Amarante ${ }^{2(0)}$
}

IUniversidade Federal de Pelotas/Instituto de Biologia Depto. de Botânica, Campus Universitário Capão do Leão, $\mathrm{s} / \mathrm{n}$ - 96010-900 - Pelotas, RS - Brasil.

2Universidade Federal de Pelotas/Centro de Ciências

Químicas, Farmacêuticas e de Alimentos, C.P. 354 - 96160000 - Capão do Leão, RS - Brasil.

3Embrapa Clima Temperado, Rod. BR 392, km 78 - 96010-

971 - Pelotas, RS - Brasil.

${ }^{*}$ Corresponding author <borellaj@gmail.com>

Edited by: Mohmmad Valipour

Received May 30, 2017

Accepted September 15, 2017
ABSTRACT: In this work, we compared nitrate-supplied plants (non-nodulated) with non-nitratesupplied plants (nodulated) under oxygen privation of root system (hypoxia) and re-oxygenation (post-hypoxia; recovery) in order to verify whether $\mathrm{N}$ sources affect the antioxidant system during oxidative stress caused by hypoxia and post-hypoxia conditions. Antioxidant enzymatic activities, ascorbate redox state, and reactive oxygen species (ROS) levels were analyzed in roots and leaves of two soybean genotypes, Fundacep 53 RR and BRS Macota at reproductive stage $\mathrm{R} 2$, during hypoxia and post-hypoxia in an experiment carried out in a hydroponic system. The antioxidant system was strongly induced in roots of nitrate-supplied plants of both genotypes, with high activity of superoxide dismutase, ascorbate peroxidase, catalase, glutathione reductase and guayacol peroxidase. It also increased reduced ascorbate and ascorbate redox state and decreased ROS production under hypoxia and recovery, while in leaves of nodulated and non-nodulated plants, a slight increase on antioxidant system was observed. Nitrate may benefit soybean plants under hypoxic conditions and subsequent re-oxygenation by inducing the antioxidant system mainly in roots to cope with ROS production and reduce oxidative damage.

Keywords: Glycine max, waterlogging, oxidative stress, antioxidative enzymes

\section{Introduction}

Waterlogging, or flooding, causes oxygen deprivation to plant roots (Limami et al., 2014) and leads to inhibition of mitochondrial oxidative phosphorylation and decrease in ATP production (van Dongen and Licausi, 2015). Besides, hypoxic conditions, mainly re-oxygenation of cells, promote a redox imbalance of mitochondria and chloroplast components leading to overreduction of electron carriers and electron leaking, producing reactive oxygen species (ROS) (Halliwell, 2006).

Several studies have reported that nitrate as $\mathrm{N}$ source exerts an important role in many plant species under hypoxia, such as soybean (Oliveira et al., 2013a, b), tobacco (Stoimenova et al., 2003) and tomato (Allègre et al., 2004) by reducing fermentation effects (lactate and ethanol accumulation) (Oliveira et al., 2013a, b) when compared to $\mathrm{N}_{2}$-fixing or $\mathrm{NH}_{4}$ supplied plants. The beneficial effects of nitrate have been attributed to nitric oxide (NO) production via the nitrate reductase activity in cytosol (van Dongen and Licausi, 2015) and within mitochondria via cytochrome $c$ oxidase (COX) (Gupta and Igamberdiev, 2011).

Most studies have shown beneficial effects of nitrate on $\mathrm{N}$ and $\mathrm{C}$ metabolism in waterlogged plants and that hypoxia followed by re-oxygenation promotes ROS production. Therefere, nitrate is also supposed to be beneficial by alleviating the effects of ROS production through the induction of the antioxidative activity of enzymes to reduce oxidative damage. Among the antioxidative enzymes, superoxide dismutase (SOD) plays a key role in scavenging superoxide radical $\left(\mathrm{O}_{2}{ }^{-}\right)$anion into hydrogen peroxide $\left(\mathrm{H}_{2} \mathrm{O}_{2}\right)$ (Simova-Stoilova et al., 2012).
Further, $\mathrm{H}_{2} \mathrm{O}_{2}$ is broken into water and dioxygen by catalase (CAT), guayacol peroxidase (GPOD) or ascorbate peroxidase (APX) (Gill and Tuteja, 2010). Non-enzymatic antioxidants, which are generally small molecules such as ascorbate (AsA), also contribute to the destruction of $\mathrm{H}_{2} \mathrm{O}_{2}$, along with glutathione and glutathione reductase (GR) enzyme via the ascorbate-glutathione cycle (Noctor et al., 1998).

Our previous work showed differences between Fundacep (tolerant) and Macota (susceptible) regarding $\mathrm{N}$ and $\mathrm{C}$ metabolism (Borella et al., 2017). Therefore, due to the lack of information regarding nitrate effects on the antioxidant status of waterlogged root system of soybean, this work investigated whether different $\mathrm{N}$ sources (nodulated and nitrate-supplied plants - nonnodulated) influence the antioxidant system of soybean plants by alleviating the oxidative effects caused by hypoxia.

\section{Materials and Methods}

\section{Plant material and growth conditions}

The study was carried out at Federal University of Pelotas - Campus Capão do Leão ( $31^{\circ} 52^{\prime} 32^{\prime \prime} \mathrm{S}$ and $52^{\circ} 21^{\prime} 24^{\prime \prime} \mathrm{W}$; altitude: $16 \mathrm{~m}$ ), with two soybean [Glycine $\max$ (L.) Merril] genotypes, Fundacep $53 \mathrm{RR}$ and BRS Macota, identified previously to respond distinctly to hypoxia (Borella et al., 2014, 2017). The experiment comprised two groups, nodulated ( $\mathrm{N}_{2}$-fixing) and nonnodulated (nitrate supplied) plants, grown in a greenhouse under natural light and temperature conditions. Plants were cultivated in $3 \mathrm{~L}$ pots ( 3 plants per pot) in vermiculite and supplied twice a week with $250 \mathrm{~mL}$ 
of nutrient solution according to the group: $\mathrm{NO}_{3}^{-}$as $\mathrm{N}$ source for non-nodulated plants and $\mathrm{N}$-free nutrient solution for nodulated ( $\mathrm{N}_{2}$-fixing), as described previously by Hoagland and Arnon (1950). Nodulated plants were inoculated when cotyledons were fully open by applying $2.5 \mathrm{~mL}$ of liquid medium containing $10^{9}$ cells $\mathrm{mL}^{-1}$ of Bradyrhizobium elkanii strain SEMIA 587 (FEPAGRO) around the stem of each plant on two occasions at 3-d intervals. Hypoxic treatments were initiated with plants at reproductive stage-R2 (Fehr et al., 1971).

For the hydroponic treatment, plants were removed from pots and the root system was carefully washed in tap water to remove vermiculite before transferring to $3 \mathrm{~L}$ pots (3 plants per pot) containing $\mathrm{N}$-free nutrient solution (for nodulated plants) or $\mathrm{N}\left(\mathrm{NO}_{3}^{-} 5\right.$ $\mathrm{mM}$ ) nutrient solution (for non-nodulated), both at onethird of normal strength of the Hoagland's solution. The whole root system was kept submersed in the nutrient solution and subjected to hypoxia by flushing $\mathrm{N}_{2}$ gas for 24 and $72 \mathrm{~h}$. Oxygen concentration in the solution was monitored with an oxygen meter (Handylab OX1). For recovery, after $72 \mathrm{~h}$ of hypoxia, plants were returned to $3 \mathrm{~L}$ pots containing vermiculite as substrate under normoxic conditions for 24 and $72 \mathrm{~h}$. At harvest, four biological replicates of roots and leaves were removed from each treatment and kept frozen $\left(-80^{\circ} \mathrm{C}\right)$ until analysis.

\section{Enzymatic activity assays}

To measure the enzymatic activities, leaves and roots ( $\pm 0.2 \mathrm{~g}$ ) were ground using liquid $\mathrm{N}_{2}$ in porcelain mortars, containing $5 \%(\mathrm{w}: \mathrm{v})$ polyvinylpolypyrrolidone (PVPP) and homogenized in $100 \mathrm{mM}$ potassium phosphate buffer, $\mathrm{pH} 7.8$, containing $0.1 \mathrm{mM}$ ethylenediaminetetraacetic acid (EDTA) and $20 \mathrm{mM}$ sodium ascorbate. The homogenate was centrifuged at 12,000 $\mathrm{g}$ for $20 \mathrm{~min}$ and the supernatant obtained was used as crude enzyme extract. All steps in the preparation of the enzyme extract were carried out at $4{ }^{\circ} \mathrm{C}$. An aliquot of the extract was used to determine protein content as described by Bradford (1976) using bovine serum albumin as standard.

The superoxide dismutase activity (SOD; EC 1.15.1.1) was tested as described by Giannopolitis and Ries (1977) by monitoring the inhibition of the nitroblue-tetrazolium (NBT) coloration at $560 \mathrm{~nm}$. The catalase activity (CAT; EC 1.11.1.6) was determined according to the method described in Azevedo Neto et al. (2006) by monitoring hydrogen peroxide consumption measuring decline in absorbance at $240 \mathrm{~nm}$. The ascorbate peroxidase activity (APX; EC 1.11.1.11) was determined according to the method described by $\mathrm{Na}$ kano and Asada (1981) measuring the rate of ascorbate oxidation at $290 \mathrm{~nm}$. The glutathione reductase activity (GR; EC 1.6.4.2) was measured according to Cakmak et al. (1993) by following the decrease in absorbance at 340 $\mathrm{nm}$ due to NADPH oxidation. The guayacol peroxidase activity (GPOD; EC 1.11.1.7) was analyzed following the method described by Urbanek et al. (1991) by monitor- ing the tetraguayacol production by reducing hydrogen peroxide at $470 \mathrm{~nm}$. The glutathione S-transferase activity (GST; EC 2.5.1.13) was performed as described by Dalton et al. (2009) by measuring absorbance at $340 \mathrm{~nm}$ using 2,4-dinitrochlorobenzene as substrate.

\section{Ascorbate content}

The contents of reduced ascorbate (AsA) and total ascorbate [(AsA + oxidized ascorbate (DHA)] were quantified as described by Arakawa et al. (1981). Tissues $(0.2 \mathrm{~g})$ were ground in $5 \%$ trichloroacetic acid (TCA), homogenized and centrifuged at $10,000 \mathrm{~g}$ for $15 \mathrm{~min}$ at $4{ }^{\circ} \mathrm{C}$. Total ascorbate from supernatant was determined after reduction of DHA by dithiothreitol (DTT). The reaction medium consisted of $5 \%$ TCA, $0.06 \%$ DTT and $0.2 \mathrm{M}$ sodium phosphate buffer, $\mathrm{pH}$ 7.0. After incubation at room temperature for $10 \mathrm{~min}, 0.24 \% \mathrm{~N}$-ethylmaleimide was added and the $\mathrm{pH}$ of each tube adjusted to between 1 and 2 with $20 \%$ TCA. Afterwards, phosphoric acid $4 \%\left(\mathrm{H}_{3} \mathrm{PO}_{4}\right)$, bathophenanthroline $0.5 \%$ and ferric chloride $0.03 \%\left(\mathrm{FeCl}_{3}\right)$ were added and incubated for $90 \mathrm{~min}$ at $30{ }^{\circ} \mathrm{C}$. The absorbance was read at 534 $\mathrm{nm}$. The ascorbate was determined as described above, but replacing the DTT for absolute ethanol in equal volume. The DHA values were obtained by the difference between the values of total ascorbate and reduced ascorbate. The ascorbate redox state was calculated as [(AsA)/ $(\mathrm{AsA}+\mathrm{DHA})] \times 100$ and expressed as percentage of reduced ascorbate from the total ascorbate (Bonifacio et al., 2011).

\section{$\mathrm{O}_{2}{ }^{--}$content}

The assay of $\mathrm{O}_{2}^{--}$content was determined according to $\mathrm{Li}$ et al. (2010). The tissues (0.2 g) were ground

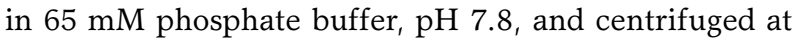
$5,000 \mathrm{~g}$ for $10 \mathrm{~min}$. The supernatant was mixed with $65 \mathrm{mM}$ phosphate buffer, $\mathrm{pH} 7.8$, and $10 \mathrm{mM}$ hydroxylamine hydrochloride, and incubated at $25^{\circ} \mathrm{C}$ for $20 \mathrm{~min}$. Then, sulphanilamide and $\alpha$-naphthylamine were added to the mixture, resulting in a final concentration of 17 $\mathrm{mM}$ and $7 \mathrm{mM}$, respectively. The solution absorbance at $530 \mathrm{~nm}$ was measured after incubation for $20 \mathrm{~min}$ at $25^{\circ} \mathrm{C}$. A standard curve with nitrite $\left(\mathrm{NO}_{2}\right)$ was used to calculate $\mathrm{O}_{2}^{\cdot-}$ generation rate.

\section{$\mathrm{H}_{2} \mathrm{O}_{2}$ content and lipid peroxidation measurement}

Hydrogen peroxide levels and lipid peroxidation were determined according to Velikova et al. (2000). The tissues $(0.2 \mathrm{~g})$ were ground in $0.1 \%(\mathrm{w}: \mathrm{v})$ trichloroacetic acid (TCA). The homogenate was centrifuged $(12,000$ $\mathrm{g}, 4{ }^{\circ} \mathrm{C}, 20 \mathrm{~min}$ ) and the supernatant was used for the analyses. An aliquot of the supernatant was added to 10 $\mathrm{mM}$ potassium phosphate buffer, $\mathrm{pH} 7.0$ and $1 \mathrm{M}$ potassium iodide to determine $\mathrm{H}_{2} \mathrm{O}_{2}$. Reaction absorbance was measured at $390 \mathrm{~nm}$. The $\mathrm{H}_{2} \mathrm{O}_{2}$ content was given on a standard curve prepared with known $\mathrm{H}_{2} \mathrm{O}_{2}$ concentrations. Lipid peroxidation was determined by using thiobarbituric acid (TBA), which determines malondial- 
dehyde (MDA) as a product of lipid peroxidation. The supernatant was added to $0.5 \%(\mathrm{w}: \mathrm{v})$ TBA in $10 \%$ TCA solution. The mixture was incubated in boiling water $\left(90{ }^{\circ} \mathrm{C}\right)$ for $20 \mathrm{~min}$; afterwards, the reaction was stopped in an ice bath for $10 \mathrm{~min}$. Then, the samples were centrifuged at 10,000 g for $5 \mathrm{~min}$ and absorbance was read at $535 \mathrm{~nm}$. The value for non-specific absorption at 600 $\mathrm{nm}$ was subtracted. The amount of MDA-TBA complex was calculated from the extinction coefficient $(\varepsilon=155 \times$ $\left.10^{3} \mathrm{M}^{-1} \mathrm{~cm}^{-1}\right)$.

\section{Statistical analysis}

Each treatment consisted of four replicates and each replicate consisted of one pot containing three plants (material pooled), in a completely randomized design. The data were analyzed by one-way analysis of variance (ANOVA). When $F$ was significant, the means of $\mathrm{O}_{2}$ availability treatments (normoxia, hypoxia, and recovery) were compared for each $\mathrm{N}$ assimilation system (nodulated or non-nodulated plants) or the $\mathrm{N}$ assimilation systems were compared for each $\mathrm{O}_{2}$ availability treatment by the Tukey's test $(p \leq 0.05)$. The statistical analyses were performed using the SAS 8.0 statistical software program (Statistical Analysis System, v. 8.0).

\section{Results}

Oxygen concentration in the solution of both nodulated and non-nodulated plants was about $6.5 \mathrm{mg} \mathrm{L}^{-1}$ under normoxia. Under hypoxia, oxygen concentration decreased rapidly to $0.5 \mathrm{mg} \mathrm{L}^{-1}$ within $5 \mathrm{~h}$, reaching 0.25 $\mathrm{mg} \mathrm{L}^{-1}$ in $24 \mathrm{~h}$ until the end of the experiment $(72 \mathrm{~h})$ (data not shown).

\section{Antioxidant enzymatic activity}

The antioxidant enzymatic system of plants subjected to hypoxia and subsequent re-oxygenation are shown in roots (Figures $1 \mathrm{~A}, \mathrm{~B}, \mathrm{C}, \mathrm{D}, \mathrm{E}$ and $\mathrm{F}$ and $3 \mathrm{~A}$, $\mathrm{B}, \mathrm{C}, \mathrm{D}, \mathrm{E}$ and $\mathrm{F}$ ) and leaves (Figures 2A, B, C, D, E and $\mathrm{F}$ and $4 \mathrm{~A}, \mathrm{~B}, \mathrm{C}$ and $\mathrm{D})$ of nodulated ( $\mathrm{N}_{2}$-fixing) and non-nodulated (nitrate-supplied) soybean plants of two genotypes, Fundacep 53 RR and BRS Macota. The enzymatic activity increased significantly in roots during hypoxia and recovery in non-nodulated plants. SOD and

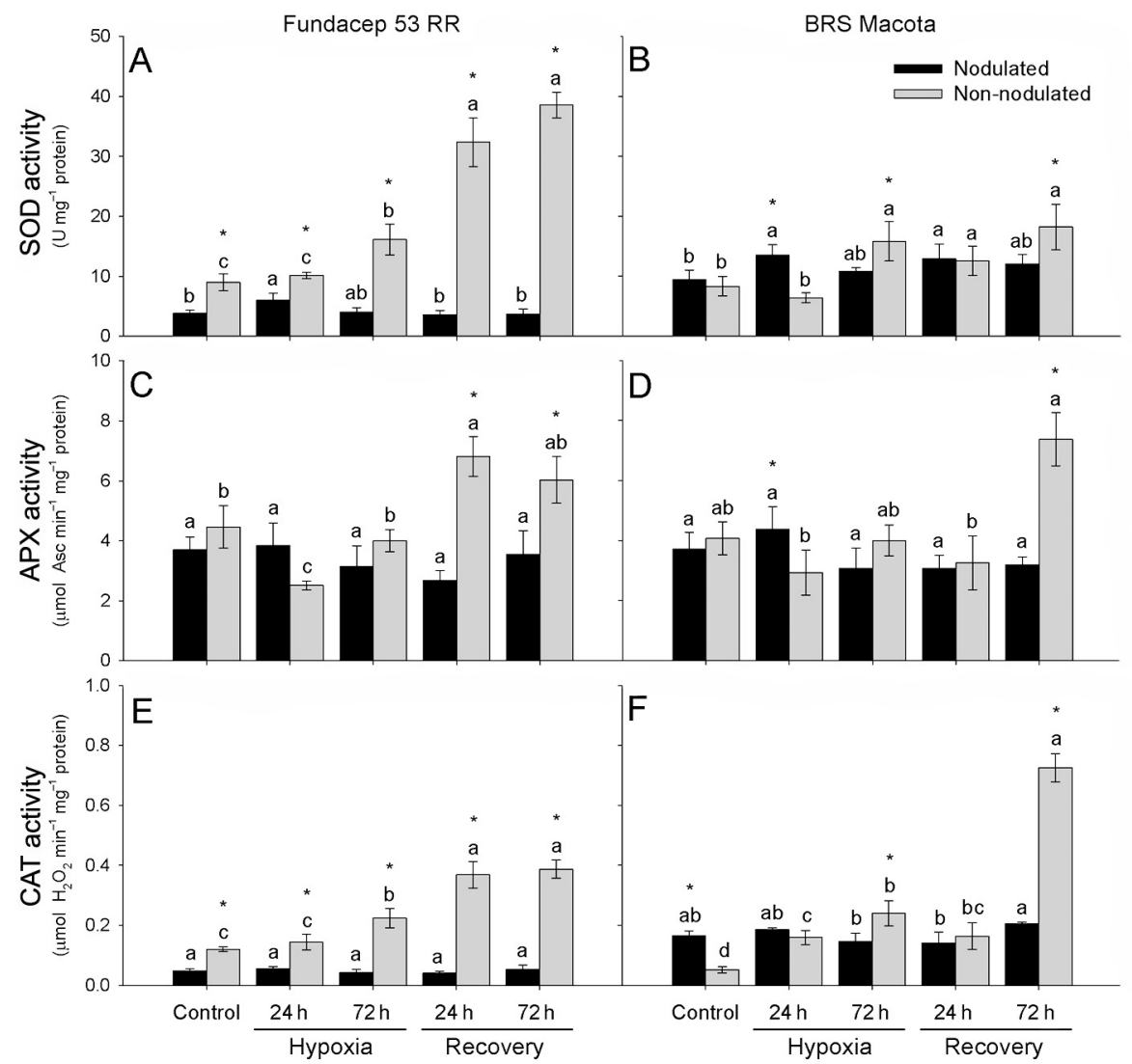

Figure 1 - Superoxide dismutase (SOD - A and B), ascorbate peroxidase (APX - C and D) and catalase (CAT - E and F) activity in roots of two nodulated and non-nodulated soybean genotypes (Fundacep 53 RR and BRS Macota) under hypoxia and recovery conditions. Means followed by the same letters do not differ by the Tukey's test $(p \leq 0.05)$ among $\mathrm{O}_{2}$ availability treatments for nodulated or non-nodulated, separately. Asterisk $\left({ }^{*}\right)$ indicates significant differences by the Tukey's test $(p \leq 0.05)$ between nodulated and non-nodulated for each $\mathrm{O}_{2}$ availability treatment. Values represent the mean $\pm \mathrm{SD}(n=4)$. 


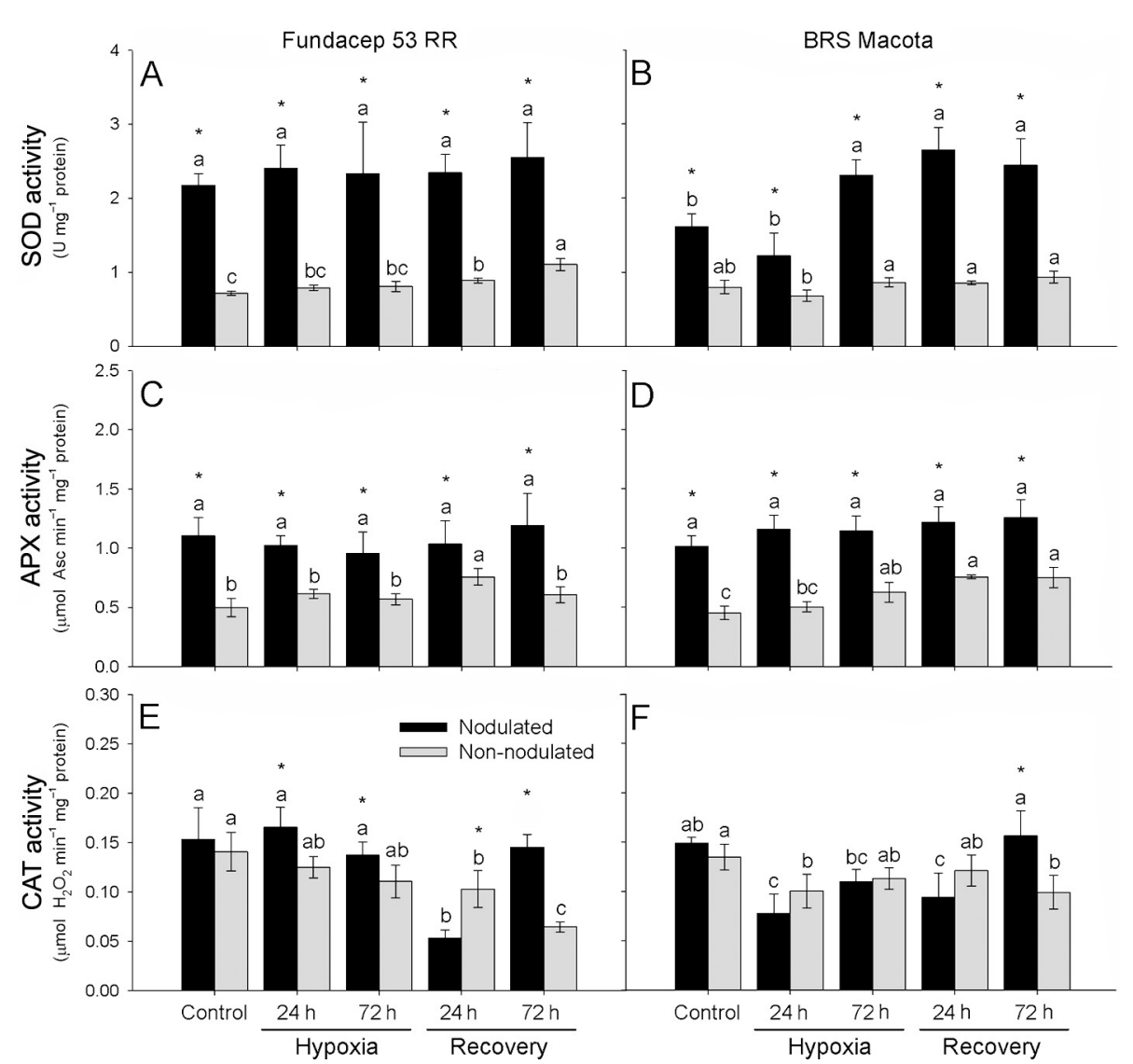

Figure 2 - Superoxide dismutase (SOD - A and B), ascorbate peroxidase (APX - C and D) and catalase (CAT - E and F) activity in leaves of two nodulated and non-nodulated soybean genotypes (Fundacep 53 RR and BRS Macota) under hypoxia and recovery conditions. Means followed by the same letters do not differ by the Tukey's test $(p \leq 0.05)$ among $\mathrm{O}_{2}$ availability treatments for nodulated or non-nodulated, separately. Asterisk $\left(^{*}\right)$ indicates significant differences by the Tukey's test $(p \leq 0.05)$ between nodulated and non-nodulated for each $\mathrm{O}_{2}$ availability treatment. Values represent the mean $\pm S D(n=4)$.

CAT increased in roots of both waterlogged non-nodulated soybean genotypes at $72 \mathrm{~h}$ and were higher than in the control during recovery with strong effect on Fundacep $53 \mathrm{RR}$. In nodulated soybean plants, an increase in SOD activity was observed at $24 \mathrm{~h}$ of hypoxia in both genotypes and remained until the end of the experiment in BRS Macota. In Fundacep 53 RR, the activity decreased with recovery. The CAT activity did not differ from that in the control during the entire experiment in both genotypes. Plants supplied with nitrate increased SOD and CAT activities by about 3-fold compared to nodulated plants in both genotypes (Figures 1A and B).

APX activity only increased upon return to normoxia in nitrate-supplied plants while did not differ in nodulated plants in both genotypes (Figures $1 \mathrm{C}$ and D). Interestingly, the APX activity was responsive during recovery with higher increase in the activity in nitrate-supplied plants and a faster increase in Fundacep 53 RR than BRS Macota (Figures 1C and D).

The enzymatic activities were different in leaves compared to roots under normoxic conditions. Despite increased SOD and APX activity with recovery in plants supplied with nitrate (Figures 2A-D), the activity of these enzymes did not change in nodulated plants, except for the SOD activity in BRS Macota at $72 \mathrm{~h}$ of hypoxia (Figure $2 \mathrm{~B})$, remaining higher even during recovery. In addition, SOD and APX activities were higher in nodulated plants than in nitrate-supplied plants (non-nodulated) in comparison with their activities in roots of both plant groups (Figures 1A-D). On the other hand, the CAT activity appears to be non-responsive in leaves (Figures $2 \mathrm{E}$ and $\mathrm{F}$ ) as it is in roots.

In addition to SOD, APX and CAT (Figures $1 \mathrm{~A}$, $\mathrm{B}, \mathrm{C}, \mathrm{D}, \mathrm{E}, \mathrm{F}$ and $2 \mathrm{~A}, \mathrm{~B}, \mathrm{C}, \mathrm{D}, \mathrm{E}$ and F), GR and GPOD activities increased in roots similarly to CAT with $72 \mathrm{~h}$ of hypoxia, although they were higher during recovery, in nitrate-supplied plants (Figures $3 \mathrm{~A}$ and B), with a pronounced increase of GR in Fundacep 53 RR. The GR activity did not increase in nodulated plants. In leaves, GR was more active during hypoxia with increased activity at $72 \mathrm{~h}$ in leaves of both genotypes in nitrate-supplied plants, while in nodulated plants, the activities were similar to those in the control (Figures $4 \mathrm{~A}$ and $\mathrm{B}$ ). In contrast, GPOD was found as the most active peroxidase 


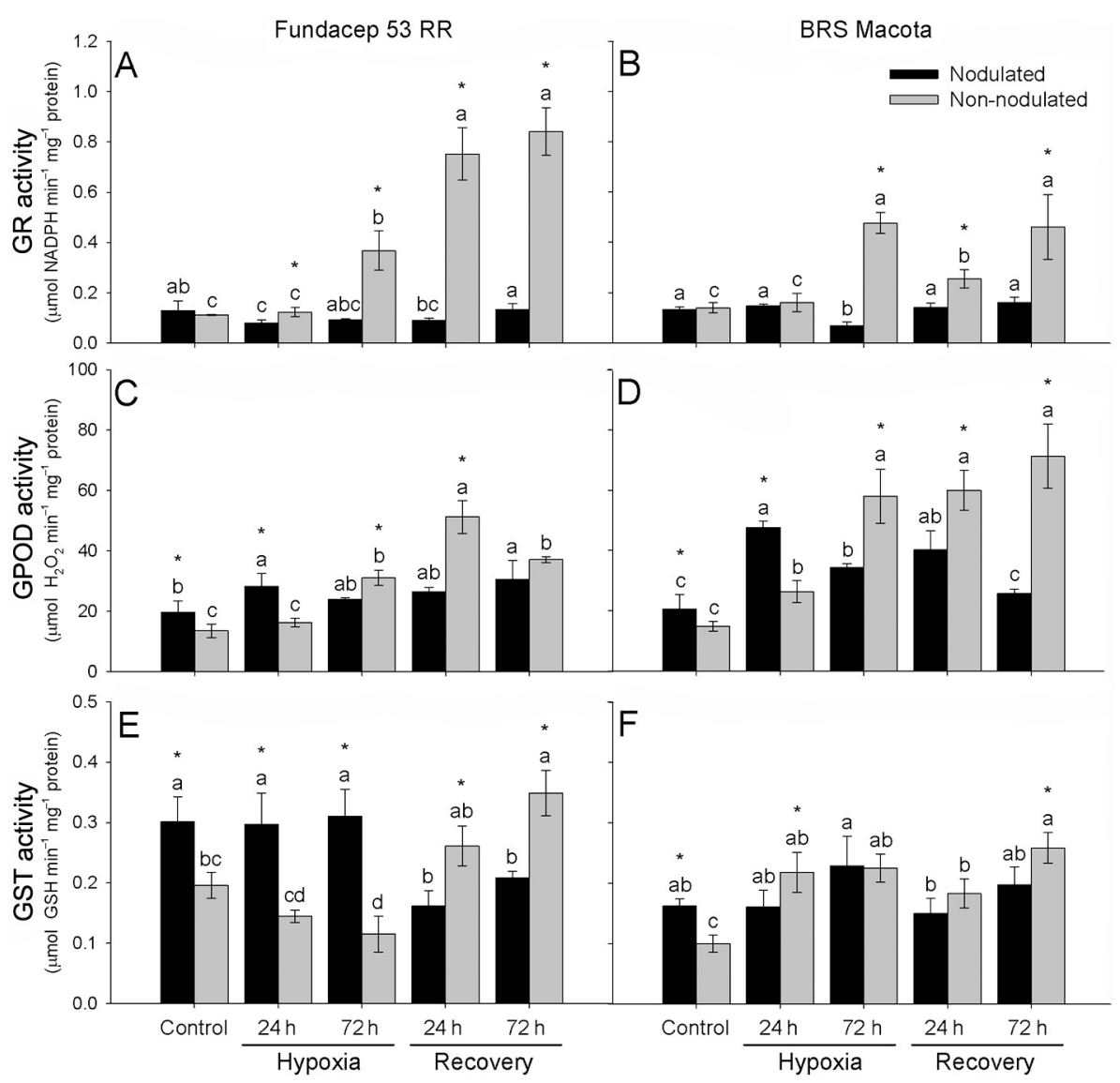

Figure 3 - Glutathione reductase (GR - A and B), guayacol peroxidase (GPOD - C and D) and glutathione S-transferase (GST - E and F) activity in roots of two nodulated and non-nodulated soybean genotypes (Fundacep 53 RR and BRS Macota) under hypoxia and recovery conditions. Means followed by the same letters do not differ by the Tukey's test $(p \leq 0.05)$ among $\mathrm{O}_{2}$ availability treatments for nodulated or non-nodulated, separately. Asterisk $\left({ }^{*}\right)$ indicates significant differences by the Tukey's test $(p \leq 0.05)$ between nodulated and non-nodulated for each $\mathrm{O}_{2}$ availability treatment. Values represent the mean $\pm \operatorname{SD}(n=4)$.

in roots under hypoxia (Figures $3 \mathrm{C}$ and $\mathrm{D}$ ), whereas no activity of this enzyme was detected in leaves.

The GST activity changed significantly in roots during hypoxia in non-nodulated plants, decreased in Fundacep $53 \mathrm{RR}$ and increased in re-oxygenation. In BRS Macota, the GST activity increased during hypoxia and was kept at high levels during recovery (Figures 3E and F). In leaves of non-nodulated plants, the GST activity increased markedly during hypoxia in both genotypes and was kept at higher levels during recovery (Figures $4 \mathrm{C}$ and D). In nodulated plants, GST was more active during hypoxia in roots and leaves (Figures 4C and D) in both genotypes.

\section{Ascorbate redox state}

In the most treatments, reduced ascorbate was higher in nitrate-supplied plants and in both genotypes. The content was higher during recovery than during hypoxia in both, roots (Figures 5A-D) and leaves (Figures $6 \mathrm{~A}-\mathrm{D})$. On the other hand, increased ascorbate redox state was higher during recovery only in non-nodulated plants in roots and leaves, and these responses were greater in BRS Macota genotype.

\section{Oxidative damage}

Superoxide, hydrogen peroxide and lipid peroxidation in roots and leaves are shown in Figures $7 \mathrm{~A}, \mathrm{~B}, \mathrm{C}$, $\mathrm{D}, \mathrm{E}, \mathrm{F}$ and $8 \mathrm{~A}, \mathrm{~B}, \mathrm{C}, \mathrm{D}, \mathrm{E}$ and $\mathrm{F}$, respectively. In roots of nitrate-supplied plants with $24 \mathrm{~h}$ of hypoxia, the content of superoxide remained low, similar to the control, and later reduced at $72 \mathrm{~h}$ of hypoxia in both genotypes. In turn, during recovery in Fundacep $53 \mathrm{RR}$, the content was below the control levels (Figures 7A and B), reflecting the SOD activity in roots (Figures $1 \mathrm{~A}$ and $\mathrm{B}$ ). In nodulated plants, the production of superoxide decreased during hypoxia and increased with the return to normoxic conditions (Figures 7A and B).

The hydrogen peroxide content was lower than in the control even under hypoxia and recovery in roots of nitrate-supplied plants than in nodulated plants (Figures $7 \mathrm{C}$ and D), probably due to the activity of enzymes that are responsive to scavenging. The level of lipid peroxida- 


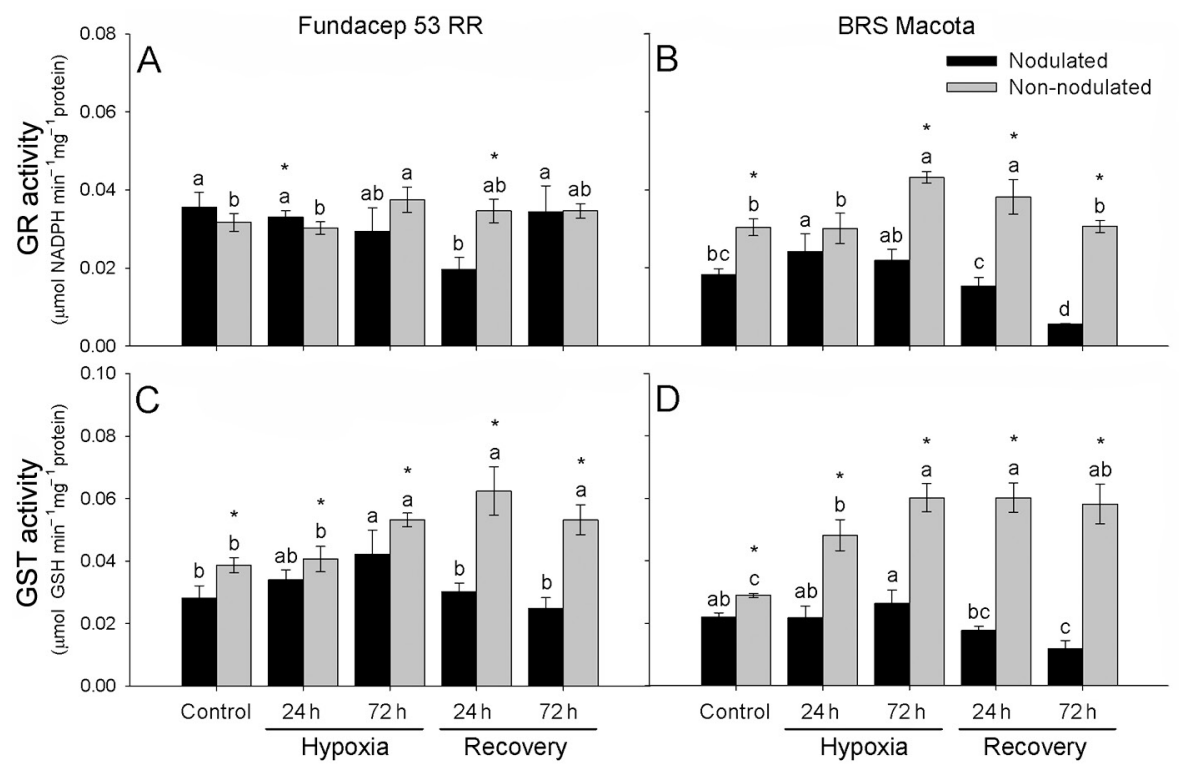

Figure 4 - Glutathione reductase (GR - A and B), glutathione S-transferase (GST - C and D) activity in leaves of two nodulated and non-nodulated soybean genotypes (Fundacep 53 RR and BRS Macota) under hypoxia and recovery conditions. Means followed by the same letters do not differ by the Tukey's test $(p \leq 0.05)$ among $\mathrm{O}_{2}$ availability treatments for nodulated or non-nodulated, separately. Asterisk $\left(^{*}\right)$ indicates significant differences by the Tukey's test $(p \leq 0.05)$ between nodulated and non-nodulated for each $\mathrm{O}_{2}$ availability treatment. Values represent the mean $\pm \operatorname{SD}(n=4)$.

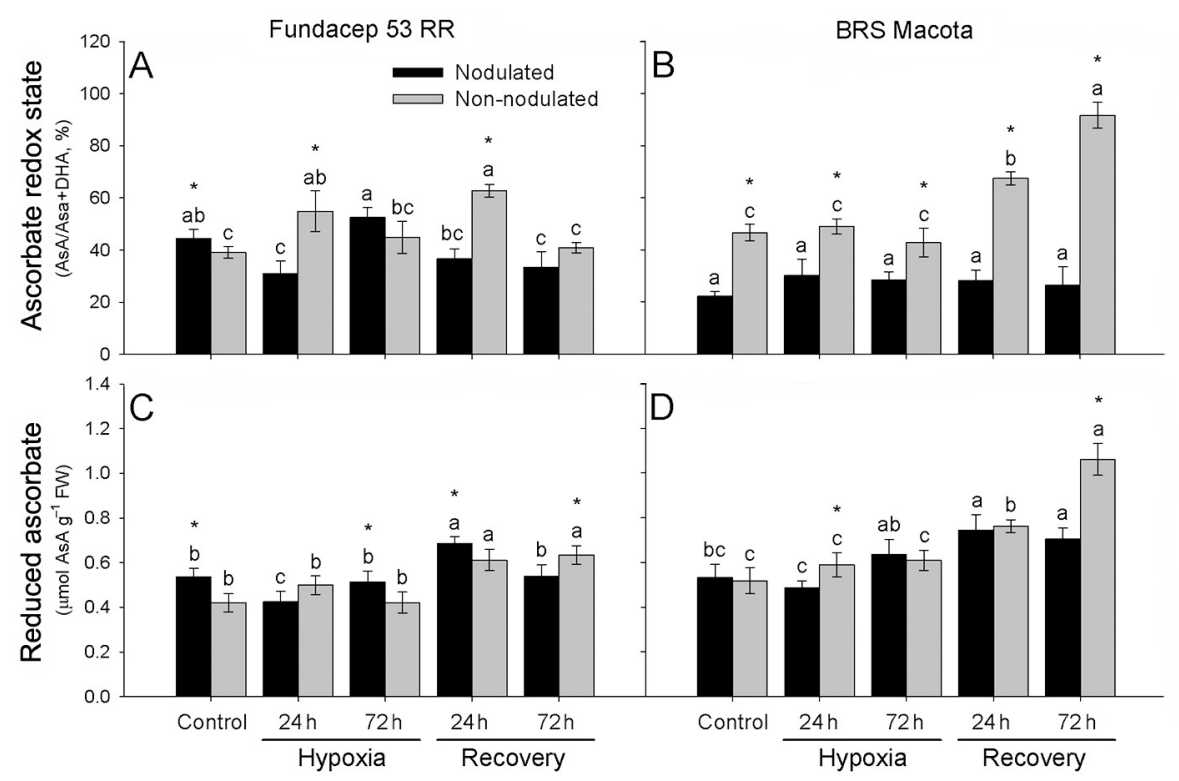

Figure 5 - Ascorbate redox state ( $A$ and $B$ ) and reduced ascorbate content ( $A s A-C$ and $D$ ) in roots of two nodulated and non-nodulated soybean genotypes (Fundacep 53 RR and BRS Macota) under hypoxia and recovery conditions. Means followed by the same letters do not differ by the Tukey's test $\left(p \leq 0.05\right.$ ) among $\mathrm{O}_{2}$ availability treatments for nodulated or non-nodulated, separately. Asterisk (*) indicates significant differences by the Tukey's test $(p \leq 0.05)$ between nodulated and non-nodulated for each $\mathrm{O}_{2}$ availability treatment. Values represent the mean \pm SD $(n=4)$.

tion decreased in roots of both genotypes during hypoxia and recovery. However, the level modulation was higher in nitrate-supplied plants in which the levels did not increase as much as in control after hypoxia in roots of nodulated plants in both genotypes (Figures $7 \mathrm{E}$ and F).
In leaves, differently from roots, an increase in superoxide production was observed in nitrate-supplied plants during hypoxia and remained at higher levels than in control even at $72 \mathrm{~h}$ of recovery. In nodulated plants, the content did not change in Fundacep $53 \mathrm{RR}$, it 


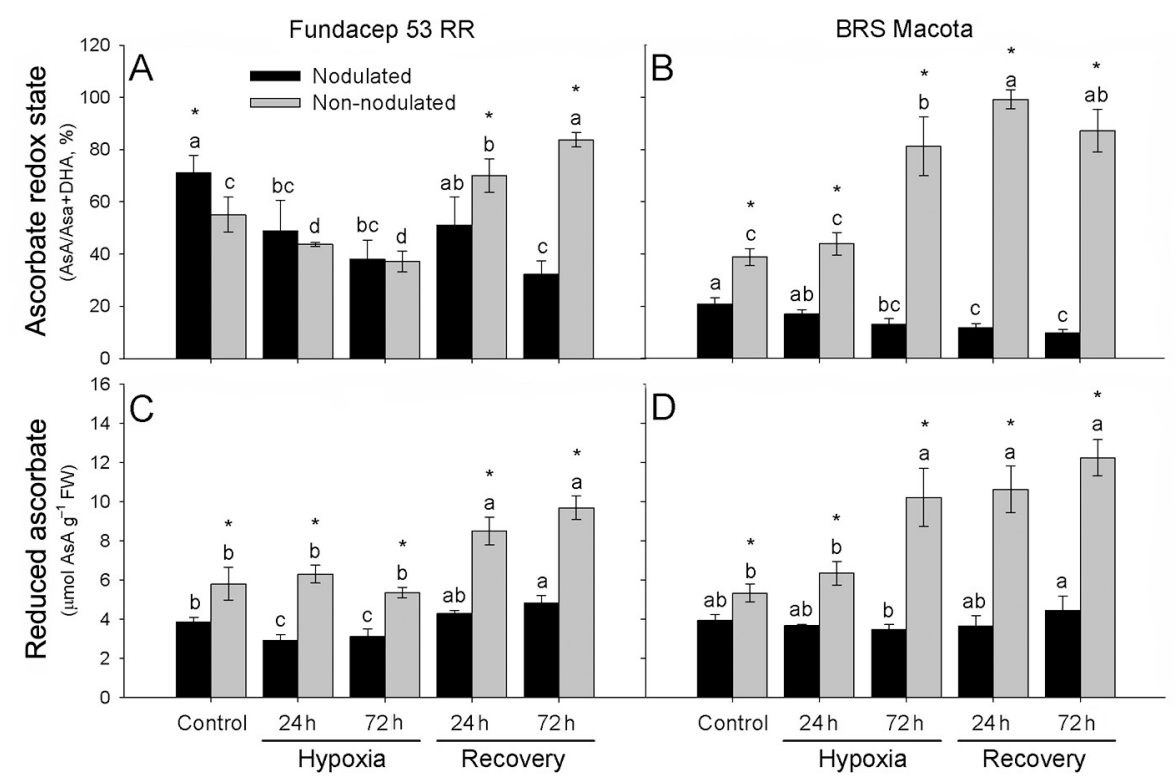

Figure 6 - Ascorbate redox state ( $A$ and $B$ ) and reduced ascorbate content ( $A s A-C$ and $D$ ) in leaves of two nodulated and non-nodulated soybean genotypes (Fundacep 53 RR and BRS Macota) under hypoxia and recovery conditions. Means followed by the same letters do not differ by the Tukey's test $(p \leq 0.05)$ among $\mathrm{O}_{2}$ availability treatments for nodulated or non-nodulated, separately. Asterisk $\left(^{*}\right)$ indicates significant differences by the Tukey's test $(p \leq 0.05)$ between nodulated and non-nodulated for each $\mathrm{O}_{2}$ availability treatment. Values represent the mean \pm SD $(n=4)$.

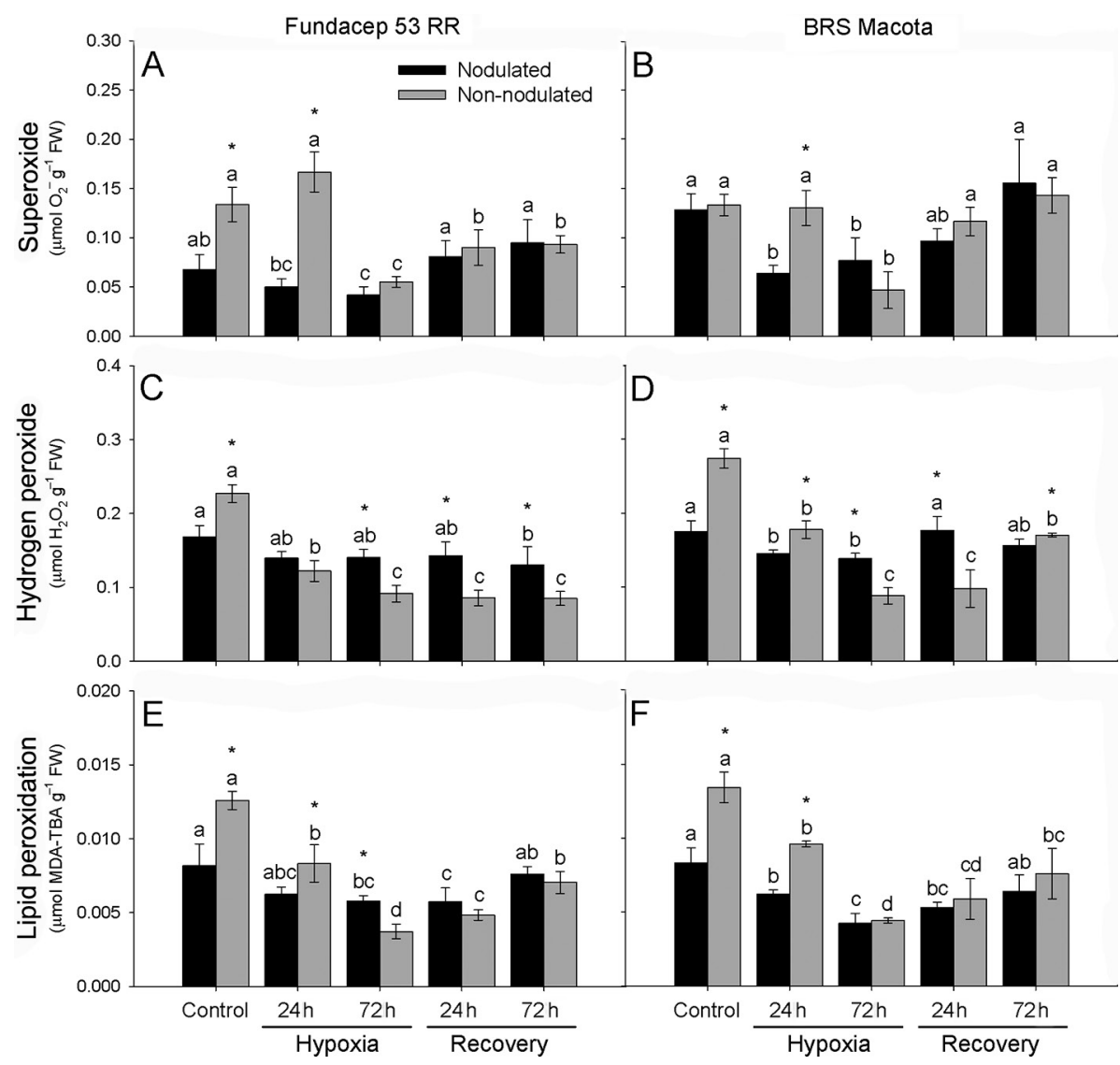

Figure 7 - Superoxide ( $A$ and $B$ ), hydrogen peroxide $(C$ and $D)$ content and lipid peroxidation $(E$ and $F$ ) in roots of two nodulated and non-nodulated soybean genotypes (Fundacep 53 RR and BRS Macota) under hypoxia and recovery conditions. Means followed by the same letters do not differ by the Tukey's test $(p \leq 0.05)$ among $\mathrm{O}_{2}$ availability treatments for nodulated or non-nodulated, separately. Asterisk $\left(^{*}\right)$ indicates significant differences by the Tukey's test $(p \leq 0.05)$ between nodulated and non-nodulated for each $\mathrm{O}_{2}$ availability treatment. Values represent the mean \pm SD $(n=4)$. 
increased in BRS Macota during hypoxia and decreased in control after $72 \mathrm{~h}$ of recovery (Figures $8 \mathrm{~A}$ and B). Hydrogen peroxide production was lower than in control at $24 \mathrm{~h}$ of hypoxia and increased later. During recovery, the content increased similarly to control in nodulated plants. In non-nodulated plants, no great changes were observed in hydrogen peroxide levels (Figures 8C and D). Lipid peroxidation did not alter significantly during hypoxia and post-hypoxia treatments in Fundacep 53 RR of nodulated plants. In BRS Macota, lipid peroxidation increased at $72 \mathrm{~h}$ of hypoxia and decreased to control levels during recovery. In non-nodulated plants, no great changes were observed in lipid peroxidation during hypoxia in comparison to normoxia in both genotypes. During post-hypoxia treatments, lipid peroxidation decreased in Fundacep $53 \mathrm{RR}$ while it did not alter in BRS Macota (Figures 8E and F).

\section{Discussion}

In this work, we described the influence of nitrate on alleviating the effects of oxidative damage caused by
ROS via induction of enzymatic and non-enzymatic antioxidants in leaves and mainly in roots, during and after hypoxia of the root system of non-nodulated plants (nitrate-supplied plants) in comparison to nodulated plants (plants assimilating ammonium, via $\mathrm{N}_{2}$ fixation) of two soybean genotypes, Fundacep 53 RR and BRS Macota. Nodulated plants were chosen rather than supplying them directly with ammonium, as ammonium is toxic and possibly influences antioxidant metabolism.

Since the study conducted by Arnon (1937), nitrate has been investigated and related to its beneficial effects in plants under oxygen deficiency (Horchani et al., 2010; Horchani et al., 2011). However, these studies have focused primarily on $\mathrm{C}$ and $\mathrm{N}$ metabolism (Horchani et al., 2010; Oliveira et al., 2013a, b; Oliveira and Sodek, 2013; Lanza et al., 2014). In agreement to experiments on nitrate benefits, a similar pattern was also observed in relation to oxidative metabolism under hypoxia and post-hypoxia conditions. In roots of non-nodulated plants, the induction of enzymes SOD, APX, CAT, GR and GPOD (Figures 1A, B, C, D, E, F and $3 \mathrm{~A}, \mathrm{~B}, \mathrm{C}, \mathrm{D}, \mathrm{E}$ and $\mathrm{F})$ and non-enzymatic antioxi-
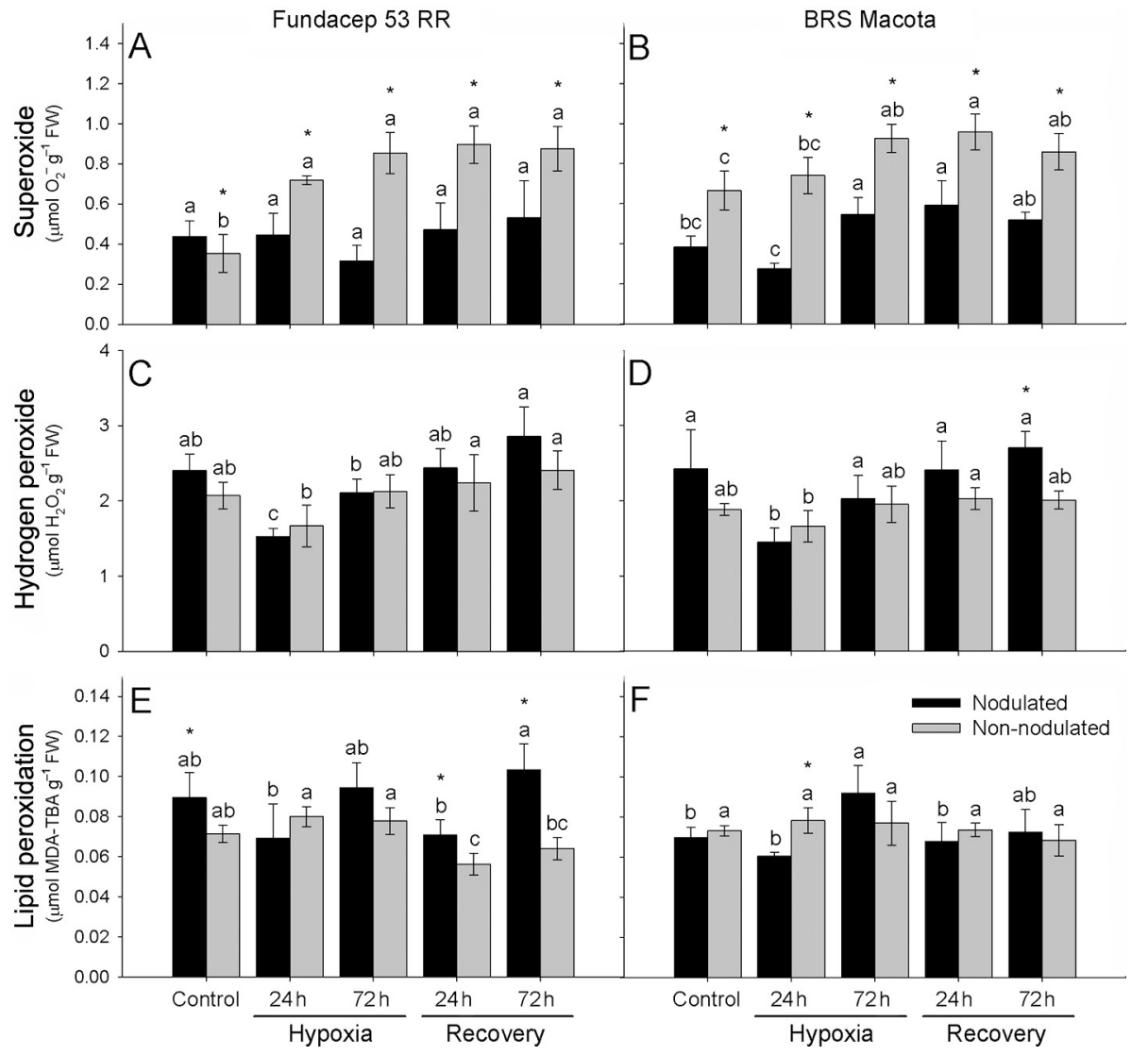

Figure 8 - Superoxide ( $A$ and $B$ ), hydrogen peroxide $(C$ and $D)$ content and lipid peroxidation $(E$ and $F$ ) in leaves of two nodulated and nonnodulated soybean genotypes (Fundacep 53 RR and BRS Macota) under hypoxia and recovery conditions. Means followed by the same letters do not differ by the Tukey's test $(p \leq 0.05)$ among $\mathrm{O}_{2}$ availability treatments for nodulated or non-nodulated, separately. Asterisk ( $\left.{ }^{*}\right)$ indicates significant differences by the Tukey's test $(p \leq 0.05)$ between nodulated and non-nodulated for each $\mathrm{O}_{2}$ availability treatment. Values represent the mean $\pm \operatorname{SD}(n=4)$. 
dants (Figures 5A, B, C and D), as well as their efficiency in scavenging ROS production (Figures 7A, B, C, D, $\mathrm{E}$ and $\mathrm{F}$ ) was markedly more efficient in comparison to the roots of nodulated plants. The ROS content in control plants of non-nodulated one was much higher than that in nodulated plants. However, the hypoxia and recovery treatments induced decreases ROS content of non-nodulated plants similarly to the ROS content in nodulated plants. Besides that, increases in enzyme activity of non-nodulated plants was above the activity of nodulated ones. These results showed that the two forms of $\mathrm{N}$ assimilation, nitrate (non-nodulated) and $\mathrm{N}_{2}$-fixing (nodulated) in plants, influence differently the antioxidant defence system under stressful conditions caused by $\mathrm{O}_{2}$ privation.

In leaves, despite the slight induction of the antioxidant system, an increase of both enzymatic and non-enzymatic antioxidants was observed (Figures 2A$\mathrm{F}, 4 \mathrm{~A}-\mathrm{D}$ and 6A-D). These results may be attributed to the short duration of hypoxia ( 3 days) to which plants were submitted. In addition, leaves were kept under normoxic conditions that may have alleviated the effects of oxygen deprivation in comparison to roots, which were directly affected.

In non-nodulated plants, an increased induction of SOD activity was observed in roots under hypoxia. During recovery, induction of SOD activity was stronger, at least in Fundacep $53 \mathrm{RR}$, while in nodulated plants, the SOD activity appears to be induced only under hypoxic conditions (Figures $1 \mathrm{~A}$ and $\mathrm{B}$ ). These results agree with the reduction of $\mathrm{O}_{2}{ }^{--}$anion production by SOD activity (Figures $7 \mathrm{~A}$ and $\mathrm{B}$ ). Furthermore, in non-nodulated roots of Fundacep $53 \mathrm{RR}_{1} \mathrm{O}_{2}^{--}$production did not reach levels of the control during recovery (Figure 7A) due to high SOD activity (Figure 1A).

As reported, SOD constitutes the first line of defence against ROS, playing an important role in detoxification of $\mathrm{O}_{2}^{--}$into $\mathrm{H}_{2} \mathrm{O}_{2}$ (Gill and Tuteja, 2010). Although ROS production increased in several plant species under hypoxia (Bai et al., 2010; Simova-Stoilova et al., 2012), it also correlated to the period of hypoxic treatment (Blokhina and Fagerstedt, 2010b). On the other hand, ROS production reduces under hypoxia conditions due to oxygen deprivation and limited functioning of the electron transport chain (Sairam et al., 2011). Moreover, distinct SOD responses to oxygen deprivation stress (anoxia and hypoxia) on different plant species have always been contradictorily described, depending on experiment design or re-oxygenation (Blokhina et al., 2003). The decrease of both $\mathrm{O}_{2}$. - and $\mathrm{H}_{2} \mathrm{O}_{2}$ production under hypoxia were attributed to a shift from aerobic respiration to fermentation with blockage of the mitochondrial site of ROS production (Sairam et al., 2011).

In nitrate-supplied plants (soybean), fermentation has been reported to be modulated by nitric oxide (NO) production, which leads to a decrease in lactate and ethanol content (Oliveira et al., 2013a, b). NO acts as an alternative pathway to recycle nicotinamide adenine dinucleotide $\left(\mathrm{NAD}^{+}\right)$from its reduced form (NADH) under low-oxygen conditions via futile NO cycle, where nitrite reduction by nitrate reductase leads to NO production in the cytosol (Limami et al., 2014; van Dongen and Licausi, 2015).

Another pathway is the reduction of nitrite via cytochrome $c$ oxidase (COX), linked to membrane proton translocation (Gupta et al., 2005; Gupta et al., 2011; Gupta and Igamberdiev, 2011; Oliveira et al., 2013b). $\mathrm{NO}$ is then oxidized to nitrate again by class-1 non-symbiotic haemoglobin (Igamberdiev and Hill, 2004), besides playing other roles in plants, such as in nodules (Sainz et al., 2015). NO has emerged as an important free radical signal in plants (Neill et al., 2008) and may affect the induction of the antioxidant system as observed in roots of nitrate-supplied plants, however, further studies are needed to clarify its effects.

ROS act in oxidative damage to membrane cells (Gill and Tuteja, 2010), with deleterious consequences and signaling roles in biological systems (Blokhina and Fagerstedt, 2010a). Among the consequences are damage to proteins, lipids, carbohydrates, and DNA, which ultimately results in cell death (Gill and Tuteja, 2010). However, further investigations are needed to confirm NO influence on antioxidant modulation.

Although NO production is enhanced in hypoxia (Gupta et al., 2011), the increased activity of antioxidant enzymes (Figures $1 \mathrm{~A}-\mathrm{F}$ and $3 \mathrm{~A}-\mathrm{F}$ ) under recovery conditions may be linked to longer exposure to hypoxia and the effects of the re-oxygenation, which are well reported as responsive for oxidative burst in the cells, leading to enzyme induction to counteract possible oxidative damage (Sairam et al., 2009; Kumutha et al., 2009; Simova-Stoilova et al., 2012)

CAT (Figures $1 \mathrm{E}$ and $\mathrm{F}$ ), GR (Figures $3 \mathrm{~A}$ and $\mathrm{B}$ ) and GPOD (Figures $3 \mathrm{C}$ and $\mathrm{D}$ ) have important roles in detoxification of $\mathrm{H}_{2} \mathrm{O}_{2}$ in roots of non-nodulated plants in both genotypes under hypoxia and recovery (Figures $7 \mathrm{C}$ and D). APX, another enzyme that acts in the scavenge of $\mathrm{H}_{2} \mathrm{O}_{2}$, was responsive to the return to normoxic conditions in roots (Figures $1 \mathrm{C}$ and $\mathrm{D}$ ) of non-nodulated plants, in agreement to gene expression and activity of APX in soybean seedling, which was responsive only after hypoxic stress (Shi et al., 2008). In nodulated plants, GPOD was important in detoxification of $\mathrm{H}_{2} \mathrm{O}_{2}$, under hypoxia and recovery (Figures 3C and D). Blokhina et al. (2003) proposed the hypothesis that CAT acts earlier in response to hydrogen peroxide production compared to other enzymes, partly explaining its high activity in roots.

APX and GR are reported as responsible for scavenging $\mathrm{H}_{2} \mathrm{O}_{2}$ (Blokhina and Fagerstedt, 2010a, b; Gill and Tuteja, 2010), along with non-enzymatic antioxidants via the ascorbate-glutathione cycle (Bonifacio et al., 2011), where GR and GSH are used to reduce AsA, oxidized by APX (Blokhina and Fagerstedt, 2010b). The redox states of GSH and AsA in wheat roots were re- 
ported to be directly dependent on oxygen concentration and reflected oxidative burst during re-aeration (Biemelt et al., 1998). Although, ROS production, $\mathrm{O}_{2}{ }^{--}$and $\mathrm{H}_{2} \mathrm{O}_{2}$, did not increase in roots (Figures 7A-F) during recovery, the increased ascorbate redox state and decreased AsA may be attributed to APX (Figures $1 \mathrm{C}$ and $\mathrm{D}$; Figure 2C and D) and GR activity (Figures 3A and B; Figure 4A and $\mathrm{B})$. On the other hand, CAT was not responsive in leaves (Figures $2 \mathrm{E}$ and $\mathrm{F}$ ) as it was in roots (Figures $1 \mathrm{E}$ and F), while APX and GR increased mainly in response to recovery, which may be explained by the fluctuation of $\mathrm{NAD}(\mathrm{P}) \mathrm{H} / \mathrm{NAD}(\mathrm{P})^{+}$ratio under hypoxia (Stoimenova et al., 2007) to keep the ascorbate-glutathione cycle operating properly, whereas CAT itself does not need $\mathrm{NAD}(\mathrm{P})$ $\mathrm{H}$ to break down $\mathrm{H}_{2} \mathrm{O}_{2}$ (Blokhina and Fagerstedt, 2010b).

On the other hand, dehydroascorbate (DHA) played an important role in the mitochondria respiratory electron transport chain in ascorbate regeneration (Blokhina and Fagerstedt, 2010b). Interestingly, DHA also participated efficiently in NO scavenge (Kytzia et al., 2006).

In addition to the efficient enzymatic system operating to scavenge $\mathrm{O}_{2}{ }^{--}$and $\mathrm{H}_{2} \mathrm{O}_{2}$ to avoid lipid peroxidation in roots (Figures $7 \mathrm{E}$ and $\mathrm{F}$ ) and leaves (Figures $8 \mathrm{E}$ and F), enzyme GST may have an important role by tagging oxidized/degraded products, such as fatty acids and nucleic acids, for removing or by acting as a peroxidase to directly scavenge peroxides and remove lipid peroxidation products (Dalton et al., 2009). ROS is dangerous because of its ability to initiate a chain reaction on polyunsaturated fatty acids that leads to lipid peroxidation (Bai et al., 2010). Free fatty acids (FFAs) are recognized as powerful uncoupling agents activating mitochondrial uncoupling proteins (UCPs), leading to a severe membrane damage and further cell death (Blokhina and Fagerstedt, 2010b).

The efficient antioxidant system as observed in roots of both genotypes (Figures $1 \mathrm{~A}-\mathrm{F}$ and $3 \mathrm{~A}-\mathrm{F}$ ) may have an important role against ROS (Figures 7A-F). Furthermore, ROS production can also be avoided by uncoupling proteins (UCPs), as ROS acts on decreasing the electrochemical gradient $\left(\Delta_{\psi \mathrm{m}}\right)$ when the mitochondria electron transport chain is over reduced (Schönfeld and Wojtczak, 2008). In addition, in non-nodulated plants, nitrate exerts an important role in the mitochondrial electron transport chain leading to ATP synthesis under hypoxia (Horchani et al., 2011) via oxidation of NADH and NADPH (Stoimenova et al., 2007).

The effect of waterlogging in roots induces stomatal closure in the shoots, once hypoxia decreases water absorption by roots and consequently hydraulic conductivity through xylem sap (Herrera, 2013). Besides, waterlogging could promote a redox imbalance of the chloroplast electron transport chain, which may have partly influenced high production of $\mathrm{O}_{2}{ }^{-}$- in leaves (Figures 8A and $\mathrm{B})$. In additon, waterlogging can also influence the reduction of chlorophyll and carotenoids contents, ethylene production and disruption of photosynthate translocation (Blokhina and Fagerstedt, 2010a, b).
The redox imbalance generated by an over reduction in the electron transport chain of chloroplasts is due to a decrease in ATP and NADPH consumption via Calvin-Benson cycle promoted by a limited $\mathrm{CO}_{2}$ entry that slows down the carboxylation reaction of Rubisco enzyme. Thus, the over reduction of ETC also leads to electron escape that react with oxygen to produce ROS (Blokhina and Fagerstedt, 2010a). In roots, waterlogging reduces the activity of mitochondrial ETC, which, in turn, reduces the possibility of electron to escape and ROS production, as reported by several authors (Azevedo Neto et al., 2006; Bai et al., 2010). In leaves, however, it is different, as ETC is driven by light absorption.

The increase in SOD activity in leaves (Figures 2A and B) may reflect $\mathrm{O}_{2}{ }^{--}$production, once $\mathrm{NO}$ was not reported to be produced from nitrite reduction in leaves under hypoxic conditions (Gupta et al., 2005), although nitrate is transported through xylem sap from roots to shoot in soybean plants (Oliveira et al., 2013a; Lanza et al., 2014) and the lack ability of leaf mitochondria to produce NO may somehow be related to photosynthesis (Gupta et al., 2005).

Altouhg genotypes Fundacep $53 \mathrm{RR}$ and BRS Macota respond distinctly to hypoxia, tolerant and sensitive, respectively (Borella et al., 2014, 2017), the antioxidative metabolism here studied was not correlated with tolerance mechanisms that differentiate genotypes and it is probably due to the short duration of flooding of the root system (Wang et al., 2009). However, tolerant species increase the activity of antioxidant enzymes to counteract the oxidative effects (Sairam et al., 2009; Simova-Stoilova et al., 2012). According to our findings and others reported in studies, nitrate exerts beneficial effects on soybean plants by inducing antioxidant enzymatic and non-enzymatic compounds that may lead to a prolonged tolerance in comparison to non-nitrate-supplied plants.

\section{Conclusions}

Our data show that nitrate exerts beneficial effects on soybean plants under hypoxic conditions and consequent re-oxygenation by inducing the antioxidant system, mainly in roots, to cope with possible oxidative damage caused by ROS production. The enzymatic antioxidant system of soybean is also much more responsive during recovery from hypoxia stress than during the period of oxygen deprivation.

\section{Acknowledgments}

We are grateful to Empresa Brasileira de Pesquisa Agropecuária (Embrapa), Monsanto and Coordenação de Aperfeiçoamento de Pessoal de Nível Superior (CAPES) for financial support and Fundação Estadual de Pesquisa Agropecuária (FEPAGRO) for providing Bradyrhizobium elkanii strain. 


\section{Authors' Contributions}

Conceptualization: Borella, J., Amarante, L., Oliveira, D.S.C., Braga, E.J.B., Oliveira, A.C.B. Data acquisition: Borella, J., Becker, R., Lima, M.C. Data Analysis: Borella, J., Becker, R., Lima, M.C., Amarante, L. Design of methodology: Borella, J., Amarante, L., Oliveira, D.S.C., Braga, E.J.B., Oliveira, A.C.B. Writing and editing: All authors have writing and approved the final version of the manuscript.

\section{References}

Allègre, A.; Silvestre, J.; Morard, P.; Kallerhoff, J.; Pinelli, E. 2004. Nitrate reductase regulation in tomato roots by exogenous nitrate: a possible role in tolerance to long-term root anoxia. Journal of Experimental Botany 55: 2625-2634.

Arakawa, N.; Tsutsumi, K.; Sanceda, N.G.; Kurata, T.; Inagaki, C. 1981. A rapid and sensitive method for the determination of ascorbic acid using 4,7-diphenyl-1,10-phenanthroline. Agricultural and Biological Chemistry 45: 1289-1290.

Arnon, D.I. 1937. Ammonium and nitrate N nutrition of barley at different seasons in relation to hydrogen-ion concentration, manganese, copper, and oxygen supply. Soil Science 44: 91-122.

Azevedo Neto, A.D.; Prisco, J.T.; Eneas Filho, J.; Abreu, C.E.B.; Gomes Filho, E. 2006. Effect of salt stress on antioxidative enzymes and lipid peroxidation in leaves and roots of salttolerant and salt-sensitive maize genotypes. Environmental and Experimental Botany 56: 87-94.

Bai, T.I.; Li, C.Y.; Ma, F.; Feng, F.J.; Shu, H.R. 2010. Responses of growth and antioxidant system to root-zone hypoxia stress in two Malus species. Plant and Soil 327: 95-105.

Biemelt, S.; Keetman, U.; Albrecht, G. 1998. Re-aeration following hypoxia or anoxia leads to activation of the antioxidative defense system in roots of wheat seedlings. Plant Physiology 116: 651-658.

Blokhina, O.; Fagerstedt, K.V. 2010a. Oxidative metabolism, ROS and NO under oxygen deprivation. Plant Physiology and Biochemistry 48: 359-373.

Blokhina, O.; Fagerstedt, K.V. 2010b. Reactive oxygen species and nitric oxide in plant mitochondria: origin and redundant regulatory systems. Physiologia Plantarum 138: 447-462.

Blokhina, O.; Virolainen, E.; Fagerstedt, K.V. 2003. Antioxidants, oxidative damage and oxygen deprivation stress: a review. Annals of Botany 91: 179-194.

Bonifacio, A.; Martins, M.O.; Ribeiro, C.W.; Fontenele, A.V.; Carvalho, F.E.L.; Margis-Pinheiro, M.; Silveira, J.A.G. 2011. Role of peroxidases in the compensation of cytosolic ascorbate knockdown in rice plants under abiotic stress. Plant, Cell and Environment 34: 1705-1722.

Borella, J.; Amarante, L.; Oliveira, D.S.C.; Oliveira, A.C.B.; Braga, E.J.B. 2014. Waterlogging-induced changes in fermentative metabolism in roots and nodules of soybean genotypes. Scientia Agricola 71: 499-508.

Borella, J.; Oliveira, H.C.; Oliveira, D.S.C.; Braga, E.J.B.; Oliveira, A.C.B.; Sodek, L.; Amarante, L. 2017. Hypoxia-driven changes in glycolytic and tricarboxylic acid cycle metabolites of two nodulated soybean genotypes. Environmental and Experimental Botany 133: 118-127.
Bradford, M.M. 1976. Rapid and sensitive method for the quantitation of microgram quantities of protein utilizing the principle of protein-dye binding. Analytical Biochemical 72: 248-254.

Cakmak, I.; Strbac, D.; Marschner, H. 1993. Activities of hydrogen peroxide-scavenging enzymes in germination wheat seeds. Journal of Experimental Botany 44: 127-132.

Dalton, D.A.; Boniface, C.; Turner, Z.; Lindahl, A.; Kim, H.J.; Jelinek, L.; Govindarajulu, M.; Finger, R.E.; Taylor, C.G. 2009. Physiological roles of glutathione S-transferases in soybean root nodules. Plant Physiology 150: 521-530.

Fehr, W.R.; Caviness, C.E.; Burmood, D.T.; Penningt, J.S. 1971. Stage of development descriptions for soybeans, Glycine max (L.) Merril. Crop Science 11: 929-931.

Giannopolitis, C.N.; Ries, S.K. 1977. Superoxide dismutases. I. Occurrence in higher plants. Plant Physiology 59: 309-314.

Gill, S.S.; Tuteja, N. 2010. Reactive oxygen species and antioxidant machinery in abiotic stress tolerance in crop plants. Plant Physiology and Biochemistry 48: 909-930.

Gupta, K.J.; Igamberdiev, A.U. 2011. The anoxic plant mitochondrion as a nitrite: NO reductase. Mitochondrion 11: 537-543.

Gupta, K.J.; Igamberdiev, A.U.; Manjunatha, G.; Segu, S.; Moran, J.F.; Neelawarne, B.; Bauwe, H.; Kaiser, W.M. 2011. The emerging roles of nitric oxide $(\mathrm{NO})$ in plant mitochondria. Plant Science 181: 520-526.

Gupta, K.J.; Stoimenova, M.; Kaiser, W.M. 2005. In higher plants, only root mitochondria, but not leaf mitochondria reduce nitrite to NO, in vitro and in situ. Journal of Experimental Botany 56: 2601-2609.

Halliwell, B. 2006. Reactive species and antioxidants: redox biology is a fundamental theme of aerobic life. Plant Physiology 141: 312-322.

Herrera, A. 2013. Responses to flooding of plant water relations and leaf gas exchange in tropical tolerant trees of a black-water wetland. Frontiers in Plant Science 4: 1-12.

Hoagland, D.R.; Arnon, D.I. 1950. The Water Culture Method of Growing Plants without Soil. California Agricultural Experiment Station, UC Berkeley, CA, USA. (Circular, 347).

Horchani, F.; Aschi-Smiti, S.; Brouquisse, R. 2010. Involvement of nitrate reduction in the tolerance of tomato (Solanum lycopersicum L.) plants to prolonged root hypoxia. Acta Physiologiae Plantarum 32: 1113-1123.

Horchani, F.; Prévot, M.; Boscari, A.; Evangelisti, E.; Meilhoc, E.; Bruand, C.; Raymond, P.; Bonconpagni, E.; Aschi-Smiti, S.; Puppo, A.; Brouquisse, R. 2011. Both plant and bacterial nitrate reductases contribute to nitric oxide production in Medicago trunculata N-fixing nodules. Plant Physiology 155: 1023-1036.

Igamberdiev, A.U.; Hill, R.D. 2004. Nitrate, NO and haemoglobin in plant adaptation to hypoxia: an alternative to classic fermentation pathways. Journal of Experimental Botany 55: 2473-2482.

Kumutha, D.; Ezhilmathi, K.; Sairam, R.K.; Srivasta, G.C.; Deshmukh, P.S.; Meena, R.C. 2009. Waterlogging induced oxidative stress and antioxidant activity in pigeon pea genotypes. Biologia Plantarum 53: 75-84.

Kytzia, A.; Korth, H.; Sustmann, R.; Groot, H.D.; Kirsch, M. 2006. On the mechanism of the ascorbic acid-induced release of nitric oxide from n-nitrosated tryptophan derivatives: scavenging of NO by ascorbyl radicals. Chemistry 12: 8786-8797. 
Lanza, L.N.M.; Lanza, D.C.F; Sodek, L. 2014. Utilization of ${ }^{15} \mathrm{NO}_{3}{ }^{-}$by nodulated soybean plants under conditions of root hypoxia. Physiology and Molecular Biology of Plants 20: 287293.

Li, C.; Bai, T.; Ma, F.; Han, M. 2010. Hypoxia tolerance and adaptation of anaerobic respiration to hypoxia stress in two Malus species. Scientia Horticulturae 124: 274-279.

Limami, A.M.; Diab, H.; Lothier, J. 2014. Nitrogen metabolism in plants under low oxygen stress. Planta 239: 531-541.

Nakano, Y.; Asada, K. 1981. Hydrogen peroxide is scavenged by ascorbate specific peroxidase in spinach chloroplasts. Plant and Cell Physiology 22: 867-880.

Neill, S.; Bright, J.; Desikan, R.; Hancock, J.; Harrison, J.; Wilson, I. 2008. Nitric oxide evolution and perception. Journal of Experimental Botany 59: 25-35.

Noctor, G.; Arisi, A.; Jouanin, L.; Kunert, K.; Rennenberg, H.; Foyer, C.H. 1998. Glutathione: biosynthesis, metabolism and relationship to stress tolerance explored in transformed plants. Journal of Experimental Botany 49: 623-647.

Oliveira, H.C.; Freschi, L.; Sodek, L. 2013a. Nitrogen metabolism and translocation in soybean plants subjected to root oxygen deficiency. Plant Physiology and Biochemistry 66: 141-149.

Oliveira, H.C.; Salgado, I.; Sodek, L. 2013b. Involvement of nitrite in the nitrate-mediated modulation of fermentative metabolism and nitric oxide production of soybean roots during hypoxia. Planta 237: 255-264.

Oliveira, H.C.; Sodek, L. 2013. Effect of oxygen deficiency on nitrogen assimilation and amino acid metabolism of soybean root segments. Amino Acids 44: 743-755.

Sainz, M.; Calvo-Begueria, L.; Pérez-Rontomé, C.; Wienkoop, S.; Abián, J.; Staudinger, C.; Bartesaghi, S.; Radi, R.; Becana, M. 2015. Leghemoglobin is nitrated in functional legume nodules in a tyrosine residue within the heme cavity by a nitrite/ peroxide-dependent mechanism. Plant Journal 81: 723-735.

Sairam, R.K.; Kumutha, D.; Ezhilmathi, K. 2009. Waterlogging tolerance: nonsymbiotic haemoglobin-nitric oxide homeostasis and antioxidants. Current Science 96: 674-682.
Sairam, R.K.; Kumutha, D.; Lekshmy, S.; Chinnusamy, V. 2011. Expression of antioxidant defense genes in mung bean (Vigna radiata $\mathrm{L}$.) roots under waterlogging is associated with hypoxia tolerance. Acta Physiologiae Plantarum 33: 735-744.

Schönfeld, P.; Wojtczak, L. 2008. Fatty acids as modulators of the cellular production of reactive oxygen species. Free Radical Biology and Medicine 45: 231-241.

Shi, F.; Yamamoto, S.; Shimamura, S.; Hiraga, S.; Nakayama, N.; Nakamura, T.; Yukawa, K.; Hachinohe, M.; Matsumoto, H.; Komatsu, S. 2008. Cytosolic ascorbate peroxidase 2 (cAPX 2) is involved in the soybean response to flooding. Phytochemistry 69: 1295-1303.

Simova-Stoilova, L.; Demirevska, K.; Kingston-Smith, A.; Feller, U. 2012. Involvement of the leaf antioxidant system in the response to soil flooding in two Trifolium genotypes differing in their tolerance to waterlogging. Plant Science 183: 43-49.

Stoimenova, M.; Igamberdiev, A.U.; Gupta, K.J.; Hill, R.D. 2007. Nitrite-driven anaerobic ATP synthesis in barley and rice root mitochondria. Planta 226: 465-474.

Stoimenova, M.; Libourel, I.G.L.; Ratcliffe, R.G.; Kaiser, W.M. 2003. The role of nitrate reduction in the anoxic metabolism of roots. I. Characterization of root morphology and normoxic metabolism of wild type tobacco and a transformant lacking root nitrate reductase. Plant and Soil 253: 155-167.

Urbanek, H.; Kuzniak-Gebarowska, E.; Herka, K. 1991. Elicitation of defense responses in bean leaves by Botrytis cinerea polygalacturonase. Acta Physiologiae Plantarum 13: 43-50.

van Dongen, J.T.; Licausi, F. 2015. Oxygen sensing and signalling. Annual Review of Plant Biology 66: 345-367.

Velikova, V.; Yordanov, I.; Edreva, A. 2000. Oxidative stress and some antioxidant systems in acid rain-treated bean plants. Plant Science 151: 59-66.

Wang, K.; Bian, S.; Jiang, Y. 2009. Anaerobic metabolism in roots of Kentucky bluegrass in response to short-term waterlogging alone and in combination with high temperatures. Plant and Soil 314: 221-229. 